\title{
Study on carbon emission accounting of warm mix asphalt mixture
}

\author{
Chengqun $\mathrm{Wu}^{1}$, Wenyu $\mathrm{Shi}^{2,3}$, Haoming Shao ${ }^{2}$ \\ ${ }^{1}$ Nanjing Vocational Institute of Transport Technology; Nanjing 211188, China \\ ${ }^{2}$ Jiangsu Engineering Technology Research Center for Energy Conservation and Emission Reduction of Modern Transportation; Nanjing \\ 211188, China \\ ${ }^{3}$ School of civil engineering and transportation, Hohai University; Nanjing 210098, China
}

\begin{abstract}
At present, the international community emphasizes reducing carbon emissions, and the national level includes carbon peaking and carbon neutralization as development goals. As a landmark material for energy conservation and emission reduction in road engineering, the research on carbon emission accounting needs to be further refined. Based on the introduction of the basic concept, development process and current situation of carbon emission accounting of warm mix asphalt mixture, this paper focuses on the most novel and recognized energy consumption accounting method and carbon emission calculation method at home and abroad. The research results of carbon emission accounting in the production, transportation and construction of warm mix asphalt mixture are introduced in detail. Finally, the research on carbon emission accounting of this material is evaluated at the present stage and prospected in the future.
\end{abstract}

\section{Introduction}

For a long time, the base material often used in road engineering construction in China is hot mix asphalt mixture, but it produces a lot of carbon dioxide in the process of mixing and construction, resulting in environmental damage. The appearance of warm mix asphalt mixture greatly reduces the temperature during mixing and construction and reduces the emission of carbon dioxide. At present, warm mix asphalt technology mainly adopts the way of adding materials to reduce the temperature, generally including organic viscosity reducer method and surfactant method. While ensuring its performance, it can reduce the mixing and compaction temperature to achieve the goal of energy conservation and emission reduction. From the perspective of energy conservation and emission reduction, this paper expounds the basic concept, development history and current situation of carbon emission accounting of warm mix asphalt mixture, analyzes and studies the best carbon emission accounting method at present, and studies the carbon emission accounting of warm mix asphalt mixture from the three aspects of production, transportation and construction.

\section{Basic concepts of carbon emission accounting of warm mix asphalt mixture}

Firstly, warm mix asphalt mixture is a method that uses some technical means to greatly reduce the mixing temperature of asphalt mixture and hardly change the performance of asphalt mixture, which is called asphalt warm mix technology

Secondly, carbon emission refers to greenhouse gas emissions, such as $\mathrm{CO}_{2}, \mathrm{CO}$ and PM (particulate matter), which are all called greenhouse gases. However, since $\mathrm{CO}_{2}$ is the main body of greenhouse gas emissions and is most well known by the general public, carbon emission can also be called carbon dioxide emission. At present, due to its own gas, carbon emission is vulnerable to the influence of temperature and pressure, generally in terms of mass $(\mathrm{kg})$ Accounting as a company.

Finally, the carbon emission accounting of warm mix asphalt mixture is a kind of research on the specific accounting of carbon emission from the three links of mixture production, transportation and construction.

\section{Development and present situation of carbon emission accounting of warm mix asphalt mixture}

\subsection{Development of warm mix asphalt (WMA)}

In 1996, European countries developed warm mix asphalt by using the method of compounding soft asphalt and emulsified asphalt, and paved the test section. In terms of road performance, the effect of warm mix asphalt is comparable to that of hot mix asphalt, but the cost is about $20 \%$ higher than HMA [1].

In 2004, the zeolite addition method was introduced in detail in the European Asphalt Parliament. The method of adding admixtures opened another stage of the 
development of warm mix asphalt technology, and then the research and development of low-temperature organic viscosity reducer was carried out in Europe and Australia. Sasobit was launched in 2005 . As a representative product of organic viscosity reduction technology, it has outstanding rutting resistance, which is due to the advantages of other additive products [2].

In 2005, warm mix asphalt technology was introduced and used for the first time in China, and a test road was paved at Badaling Expressway [3]. Subsequently, asphalt foam technology, organic additive method, mineral asphalt method and other related asphalt technologies have been introduced into China.

With the development of warm mix asphalt technology, ten kinds of warm mix additives have been developed, and four main technical methods have been developed: asphalt mineral method, emulsified asphalt warm mix method, organic additive method and foam asphalt warm mix method. In recent years, the research on warm mix asphalt technology has never stopped, and relevant road paving has been carried out. Therefore, its development prospect must be unanimously recognized by all countries and has unlimited potential.

\subsection{Development of carbon emission accounting of warm mix asphalt mixture}

The earliest Research Institute on carbon emission of warm mix asphalt mixture in China began in 2010, and there are not many such studies and innovative achievements in recent ten years. In 2010, Cheng Ling, $\mathrm{Wu}$ Jiazheng and others proved that the warm mixing technology is superior to the hot mixing technology from the perspective of energy conservation and emission reduction by means of measuring energy consumption through experiments [4].

Since then, domestic research has basically focused on three aspects: production, transportation and construction, and the study of carbon emission effect from different types of warm mix agents. So far, the study of carbon emission of warm mix asphalt mixture is relatively comprehensive, but its own impact on energy conservation and emission reduction effect The impact of different construction processes on its carbon emission is still a blank in this field, and further research is needed to fully explain its future development.

\section{Study on carbon emission accounting method of warm mix asphalt mixture}

\subsection{Research on energy consumption accounting method}

Among the three main activities of warm mix asphalt mixture, the main energy consumption is electricity, diesel, gasoline and natural gas. These energy consumption can be obtained by indirect or direct measurement of equipment. For example, electric energy can be indirectly obtained by measuring the use of standard coal in thermal power plants; Diesel fuel can be obtained by making specific statistics on the fuel consumption per $100 \mathrm{~km}$ of similar models.

According to the research of Yang Bo [5] and others on the quantitative estimation method of energy consumption and emission in the construction stage of asphalt pavement, they adopt the life cycle method (LCA), which is widely used at home and abroad, to quantitatively evaluate the environmental impact of process projects. It has the advantages of systematicness and comprehensiveness, and fully considers the consumption of various materials and energy in each stage of the life cycle of asphalt pavement, So as to realize the compilation and evaluation of input, output and potential environmental impact in the life cycle of a product system. They divided the quantitative estimation methods of life cycle energy consumption in the stage of asphalt pavement construction into actual measurement method, theoretical method and quota method. Among them, the actual measurement method pays attention to field measurement and statistics according to the energy consumption generated by the operation of specific equipment, but its scope of application is relatively limited; The theoretical rule is to calculate the energy consumption according to the energy consumption parameters specified during equipment production, which is representative to a certain extent; The quota method integrates the actual measurement method and the theoretical method, and is based on the project quota managed and improved by the national authoritative department. It is very representative, but it is only applicable to the construction technology and mechanical equipment within the specified range.

\subsection{Research on carbon emission accounting based on emission factors}

\subsubsection{Carbon emission factor.}

At present, for the quantitative measurement of carbon emissions, only a few institutions can directly measure the quality of carbon emissions. Most of the other quantitative measurements are quantified and analyzed by emission factors. For most European and American countries, the method of emission factors has long become the basic method for their carbon emission measurement, However, China is only in the field of road vehicle exhaust emission in the field of transportation through quantitative analysis of emission factors. Therefore, at present, the most widely used research method is the emission factor method, which is worthy of reference and innovation by subsequent researchers.

The so-called emission factor refers to the relative value of gas emission generated by unit activity. In the main activity of warm mix asphalt mixture, the carbon emission generated by each ton of mixture is called the carbon emission factor of production activity, and the carbon emission generated by each ton of fuel or other energy consumed by transportation vehicles is called the carbon emission factor of transportation activity, The carbon emission generated by each ton of fuel oil or other energy 
consumed by mechanical equipment is called the carbon emission factor of construction activities.

\subsubsection{Carbon emission factor selection.}

The more complex research process is to determine the emission factors, which are also different in different countries. As an accounting study, emission factors given by some authorities as shown in Table 1 are generally used as a reference.

Table 1 emission factor research institutions

\begin{tabular}{|c|c|c|}
\hline $\begin{array}{c}\text { Serial } \\
\text { number }\end{array}$ & $\begin{array}{c}\text { Organization } \\
\text { type }\end{array}$ & Organization name \\
\hline 1 & $\begin{array}{l}\text { international } \\
\text { body }\end{array}$ & $\begin{array}{c}\text { IPCC (United Nations } \\
\text { Intergovernmental } \\
\text { Panel on climate } \\
\text { change) }\end{array}$ \\
\hline 2 & $\begin{array}{l}\text { international } \\
\text { body }\end{array}$ & $\begin{array}{c}\text { EPA (National } \\
\text { Environmental } \\
\text { Protection Agency) }\end{array}$ \\
\hline 3 & $\begin{array}{l}\text { international } \\
\text { body }\end{array}$ & $\begin{array}{c}\text { EEA (European } \\
\text { Environment Agency) }\end{array}$ \\
\hline 4 & $\begin{array}{l}\text { international } \\
\text { body }\end{array}$ & $\begin{array}{c}\text { Japan Energy } \\
\text { Economy Research } \\
\text { Institute }\end{array}$ \\
\hline 5 & $\begin{array}{l}\text { international } \\
\text { body }\end{array}$ & $\begin{array}{l}\text { Chinese Academy of } \\
\text { Engineering }\end{array}$ \\
\hline 6 & $\begin{array}{l}\text { international } \\
\text { body }\end{array}$ & $\begin{array}{l}\text { Energy Research } \\
\text { Institute of national } \\
\text { development and } \\
\text { Reform Commission }\end{array}$ \\
\hline 7 & $\begin{array}{l}\text { Urban } \\
\text { institutions }\end{array}$ & $\begin{array}{c}\text { Xiangtan Statistical } \\
\text { Yearbook (2004) }\end{array}$ \\
\hline
\end{tabular}

\subsubsection{Research on carbon emission accounting method.}

According to the guidance given in the 2006 IPCC guidelines for national greenhouse gas inventories, for greenhouse gas emissions, the general carbon emission calculation method is: emission = activity level multiplied by emission factor. Activity level refers to the quality of carbon emissions per unit activity $(\mathrm{kg})$, and the emission factors are selected according to the data given by major authorities. In addition, the guide also gives guidance on different calculation methods of carbon emission methods in different economic sectors. According to different sources of carbon emission, it is roughly divided into four categories: energy activities, industrial production, agriculture, forestry, land and waste disposal [6].

First of all, the calculation method of carbon emissions from energy activities. This kind of carbon emissions is obviously the main source of greenhouse gas emissions in the world today, because at present, the dependence on fossil fuels such as oil and coal is still at a considerable level in every country in the world. Our daily travel, diet and life, even education and medical treatment are inseparable from energy activities, and energy activities are inevitable According to the 2006 IPCC guidelines for national greenhouse gas inventories, there are three calculation methods that can be used to calculate the carbon emissions from fossil fuel combustion.

Method 1 carbon emission = the quantity of fossil energy burned multiplied by the average emission factor. The quantity of fossil energy burned here shall be selected according to the statistical data given by the region or country, and the emission factor can be used for all relevant greenhouse gases. However, due to the quality difference between gases, when calculating the emission of carbon dioxide, the gas containing " $\mathrm{C}$ " shall be considered first As the main body of greenhouse gas, the accuracy of carbon dioxide under this method can be improved to a high level. However, for others, such as methane and NOx, the combustion technology and conditions determine their emission factors. Due to different equipment and different development periods, the technical conditions are significantly different. Therefore, The carbon emissions of such gases are very different based on this method.

Method 2 carbon emission $=$ the quantity of fossil fuels burned multiplied by the average emission factor of a specific country. The statistical method of the quantity of fossil fuels burned here is the same as that of method 1 , but the selection of emission factors is not based on the emission factor data provided by IPCC, but based on the localization factors such as domestic fuel combustion characteristics and combustion technology of different countries, Such emission factors are more local and reliable, the calculation results of carbon emissions tend to be reasonable, and have more stability and authenticity for long-term monitoring and calculation of carbon emissions.

Method 3 carbon emission $=$ the quantity of fossil fuels burned under special measurement conditions multiplied by the average emission factor of a specific country. Compared with scheme 2, the quantity of fossil fuels here is not monitored by theoretical method and quota method, but measured according to the detailed emission model or the data given by a single plant. The cost incurred by using this method It is expensive to use and needs to continuously monitor the combustion gas, so it is too redundant for carbon dioxide emission accounting. On the contrary, it is very necessary to monitor other pollutants (such as $\mathrm{SO}_{2}, \mathrm{NOx}$, etc.). In addition, if the flow rate of fuel is difficult to measure or changes greatly, continuous monitoring can also ensure the measurement accuracy. Secondly, in industrial production, the calculation method of carbon emission. The carbon emission of industrial production is different from the direct combustion of fossil fuels. Its carbon emission is more likely to be the indirect combustion of fossil fuels into a product or a micro chemical reaction, such as chemical industry, metal industry, mining industry, etc.

Taking cement production as an example, limestone containing calcium carbonate $\left(\mathrm{CaCO}_{3}\right)$ is usually transformed into lime $(\mathrm{CaO})$ by heating or calcination At this time, its by-product $\mathrm{CO}_{2}$ will be released, and then lime will be mixed into raw materials for reaction to produce clinker, i.e. calcium hydrosilicate. Therefore, the carbon emission here has its specific calculation method: carbon emission $=$ clinker output multiplied by clinker 
emission factor, and clinker emission factor $=$ lime content multiplied by carbon dioxide relative molecular mass ratio / lime relative molecular mass ratio 。

Furthermore, the calculation method of carbon emissions from agriculture, forestry and land. The carbon emissions from agriculture, forestry and land are mainly the respiration and decomposition of animals and plants, or the combustion of some specific organic substances, such as grassland and forest seasonal fires. The main forms of carbon emissions are $\mathrm{CO}_{2}, \mathrm{~N}_{2} \mathrm{O}$ and $\mathrm{CH}_{4}$, in which carbon dioxide comes from the atmosphere and ecosystem; and $\mathrm{CH}_{4}$ is mainly the interaction between animal manure and soil $\mathrm{N}_{2} \mathrm{O}$ is an additional product of nitrification and denitrification.

The calculation of carbon emissions from agriculture, forestry and land is similar to the above two calculation methods. Refer to the 2006 IPCC guidelines for national greenhouse gas inventories, its calculation method is similar to the carbon emission of energy activities, and also has three methods. The activity level data collection method of method 123 is similar to the carbon emission of energy, and the selection of carbon emission factors is also divided into two forms: international general and national specific.

Finally, the carbon emission calculation method of waste disposal. Compared with $\mathrm{CO}_{2}$ as the main source of emissions from agriculture, forestry and land, the carbon emission of waste is mainly methane $\left(\mathrm{CH}_{4}\right)$ The main sources are solid waste landfill, domestic sewage, industrial wastewater and other forms that are prone to produce methane. Generally, the first-order attenuation method is used to calculate the carbon emission of methane gas generated by solid waste landfill, specifically, the solid waste generation multiplied by the solid waste treatment rate multiplied by the methane carbon emission factor.

\section{Study on carbon emission accounting of warm mix asphalt mixture in the whole process}

\subsection{Study on carbon emission accounting in the production process of warm mix asphalt mixture}

The Canadian Asphalt Pavement Association once tracked the carbon footprint of a road with a total length of $2.4 \mathrm{~km}$. It was found that the production and preparation of mixture accounted for $73 \%$ of the total carbon emission, the site transportation accounted for $24 \%$ of the total, and the power consumption at the construction site was only $1 \%$ of the carbon emission [7]. Therefore, the production process of warm mix asphalt mixture not only produces a lot of carbon emissions, but also the focus of many carbon emission accounting research. In its production process, its energy consumption is related to carbon emission, such as aggregate transportation, warm mix production, aggregate screening, asphalt melting and transportation, mixture mixing, etc. Due to the combustion of fuel and the consumption of electric energy, these links lead to the output and emission of a large number of greenhouse gases, such as $\mathrm{N}_{2} \mathrm{O}, \mathrm{CO}_{2}, \mathrm{CH}_{4}$, etc.

According to the project example [8], as a fast track connecting Northeast China and East China, Tangjin Expressway selected some covered sections and built experimental sections in 2017, using warm mix and hot mix asphalt technology respectively. The test formula used is: $5 \%$ of base asphalt, Evotherm warm mix agent, 5\% of asphalt, AC-13 asphalt mixture. Both mixtures are mixed in the same mixing plant, and the mixer model and raw material transportation vehicle type are the same. Then, the carbon emissions of aggregate stacking, asphalt heating, aggregate heating and mixture mixing are calculated and analyzed. The test results show that the carbon emissions of site stockpile and mixture mixing are exactly the same, and the biggest difference is in the asphalt heating stage. Due to the addition of warm mixing agent, the melting point of warm mixed asphalt has decreased by 200-300 compared with hot mixed asphalt, which greatly reduces the heat release, thus greatly reduces the carbon emissions and has a wider popularization prospect.

In addition, the research on carbon emission and energy consumption of the overall mixing equipment [9] confirmed that in the links of aggregate and asphalt heating, warm mixed asphalt mixture has an advantage, and the energy consumption and carbon emission of the mixing equipment are relatively small, which can effectively reduce the energy consumption and carbon dioxide emission in the mixing process. In addition, the study also applies to a variety of mixture types (such as AC-10, AC-16, AC-20, SMA-10, OGFC-16, etc.) the carbon emission accounting of mixing equipment is studied. The research shows that the carbon emission of warm mixing is always lower than that of hot mixing for any type of mixture; the energy consumption and carbon emission of the same type of mixture gradually decrease with the increase of nominal particle size; among different mixture types, OGFC is the largest, SMA is the second, and $\mathrm{AC}$ is the second Minimum. These conclusions also prove that the current selection of mixture in road engineering is indeed the preferred AC (continuous dense mixture), which can fully reflect the advantages of warm mix asphalt mixture in the production process, and make the development of warm mix asphalt technology become the key direction of road energy conservation and emission reduction.

\subsection{Study on carbon emission accounting during transportation and construction of warm mix asphalt mixture}

The research on carbon emission accounting during asphalt mixture transportation mainly includes two aspects: one is the carbon emission accounting of raw materials transportation stage, that is, driving trucks to transport raw materials such as aggregate, warm mix, asphalt and mineral powder from their location to the construction site or processing plant; The other is the mixture transportation stage, that is, the carbon emission accounting generated by driving the dump truck to 
transport the mixture from the mixing plant to the construction site. At this stage, the vehicle types generally include dump truck, truck, powder transport vehicle, asphalt tanker, etc. the fuel used by these vehicles is generally diesel, and the measurement unit is (L). In terms of transportation, the difference is small. Therefore, no relevant research has been carried out in this regard.

The research on carbon emission accounting during asphalt mixture construction includes two aspects: one is the research on carbon emission accounting during paving. Since this stage cannot be continuous and must undergo multi-layer paving, the calculation of energy consumption of paver needs to be recorded carefully for many times; On the other hand, it is the research on carbon emission accounting during compaction. The temperature generated during initial compaction is high, so its carbon emission is higher than that in the other two stages. Therefore, it is necessary to measure the main energy consumption and carbon emission accounting in the initial compaction stage. At present, there are three types of commonly used rollers: drum roller, vibratory roller and tire roller. For pavement construction, asphalt concrete paver is generally selected.

According to the study on pollutant emission during the construction of warm mix asphalt mixture [10], the pollution emission of several asphalt mixtures during construction is compared, and the indoor experiment is supplemented considering the relatively short test section and short sampling time at the construction site. The results show that compared with hot mix asphalt mixture, TOC (organic gaseous matter) emission is reduced by more than $50 \%$, and TPM (total particulate matter) emission is reduced by $90 \%$.

In addition, according to the study on the compaction performance of warm mix asphalt mixture [11], Sasobit warm mix agent, AC-16 mixture and 4.7\% matrix asphalt are used for grading composition. The rotating compaction method is used, and the rotating compaction energy index is used as the evaluation criterion to test its compaction performance. The results show that warm mix asphalt mixture is easy to compact, and the lower the compaction work required. Therefore, it is indirectly concluded that in the paving and compaction stage, the mechanical energy consumption of warm mixed asphalt mixture is less, and its carbon emission is also low.

\section{Conclusion}

(1) The research on energy consumption accounting mainly uses three methods: actual measurement method, theoretical method and quota method. These three methods are basically the three basic frameworks of this kind of research, and their basic contents and basic development have been determined. On its theoretical development, after all, it is only used as a measurement method and does not need more in-depth research. However, as a specific link of measurement, in-depth research can be carried out on specific steps, such as the research and innovation of measurement instruments under the actual measurement method, and so on.
(2) Research on carbon emission accounting, under the guidance of the international organization IPCC on carbon emission accounting for multiple economic sectors, the carbon emission factor method, as an international general method, has been widely recognized in the international community. Undoubtedly, the universality and economy of its accounting have become the two factors most valued by all countries and regions. However, in some specific economic sectors, there are still blank areas of carbon emission accounting, and for some countries, the local average carbon emission factor bank and carbon emission accounting model have not been established. Therefore, these parts can be further improved in future research.

(3) The research on carbon emission accounting in the production process of warm mix asphalt mixture is the most studied aspect. It has the greatest impact on energy conservation and emission reduction, especially in the links of asphalt heating and aggregate heating. However, there is still a lack of a specific evaluation system that can be used to evaluate the advantages and disadvantages of its carbon emission. Such a system should not only consider the reduction of carbon emission, but also put the road performance of the mixture in the same position. In addition, the impact of different types of warm mix agents on carbon emission accounting and refinement of production process need to be further explored.

(4) Research on carbon emission accounting during transportation and construction of warm mix asphalt mixture, there is no obvious gap between these two links and ordinary asphalt mixture, and the economic effect of the research is low. At present, there is basically no specific detailed research. However, with the continuous substitution of fossil fuels by clean energy, such carbon emission research has its development prospect in the fuel substitution of mechanical equipment.

\section{References}

1. Li Zhongkai, practice of warm mix asphalt mixture technology in Europe. Sino foreign highway, 2010. 30 (04): 286-291

2. Yang Xiaojuan, Li Shuming and Shi Baohua, technology and application analysis of warm mix asphalt mixture. Petroleum asphalt, 2007 (04): 58-61

3. Li Yulei, research on application technology of warm mix asphalt mixture, Chang'an University, 2017

4. Cheng Ling et al., quantitative study on energy conservation and emission reduction effect of warm mix asphalt paving. Journal of environmental engineering, 2010.4 (09): 2151-2155

5. Yang Bo, et al., study on quantitative estimation method of energy consumption and emission in asphalt pavement construction stage. Zhongwai highway, 2014. 34 (01): 7-13

6. Cheng Hao, how to calculate carbon emissions -2006 IPCC guidelines for national greenhouse gas inventories. China Statistics, 2014 (11): 28-30

7. Wu Junwei, development and application of carbon emission calculation and analysis model of road 
engineering. Urban roads, bridges and flood control, 2011 (07):248-250 + $274+20$

8. Zhang $\mathrm{Xu}$, comparative case study on carbon emissions of warm mix and hot mix asphalt mixtures. China Municipal Engineering, 2018 (05): 92-94 + 113-114

9. Li Shouwei, research on energy consumption and carbon emission of asphalt pavement construction. Highway engineering, 2015. 40 (02): 257-259+305

10. Chen Zhipeng, impact analysis of warm mix asphalt mixture construction on environmental protection. Highway and automobile transportation, 2021 (01): $148-150$

11. Zou Xiaobin, Sasobit, compaction performance of warm mix asphalt mixture. Fujian communications technology, 2017 (02): 5-7+106 